\title{
Longitudinal trends in and tracking of energy and nutrient intake over 20 years in a Dutch cohort of men and women between 13 and 33 years of age: The Amsterdam growth and health longitudinal study
}

\author{
G. Bertheke Post, Wieke de Vente, Han C. G. Kemper* and Jos W. R. Twisk \\ Institute for Research in Extramural Medicine, Amsterdam Growth and Health Research Group, Faculty of Medicine, Vrije \\ Universiteit, vd Boechorststraat 7, 1081 BT Amsterdam, The Netherlands
}

(Received 8 July 1999 - Revised 21 August 2000 - Accepted 21 August 2000)

\begin{abstract}
The purpose of the present study was to describe the longitudinal development of nutrient intake and to determine the stability of this intake from adolescence into adulthood. Longitudinal data of the Amsterdam Growth and Health Longitudinal Study were analysed; the dietary intake of 200 subjects (males and females) was repeatedly measured (eight times) over a period of 20 years, covering the age period of 13-33 years. Dietary intake was determined with the detailed crosscheck dietary history interview. With use of multivariate ANOVA for repeated measurements, trends in macro- and micronutrients over time and differences between genders were analysed. Furthermore, stability coefficients, corrected for time-dependent (biological age) and time-independent covariates (gender) were calculated, taking into account all the measurements. The results showed significant $(P<0.001)$ time and gender effects for energy intake $(\mathrm{kJ})$ and the following macronutrients: protein ( $\mathrm{g}$ and $\%$ total energy supply), fat $(\mathrm{g})$ and carbohydrate (g). Interaction effects between time and gender diminished when the macronutrients were calculated as a percentage of total energy intake. The micronutrients $\mathrm{Ca}, \mathrm{Fe}$ and vitamins changed significantly $(P<0.001)$ over time and showed an interaction effect with gender, with the exception of cholesterol intake $(\mathrm{mg} / \mathrm{MJ})$, which did not show an interaction effect of time and gender. The tracking of the nutrient intake showed relatively low but significant $(P<0.05)$ stability coefficients for all macro- and micronutrients $(0 \cdot 28-0.52)$. In conclusion, dietary intake does change considerably over time, with the exception of polyunsaturated fat intake (\% total energy supply) for both males and females and fat intake in females. Furthermore, stability coefficients for nutrients appeared to be low to moderate. Although these coefficients may be somewhat attenuated as a result of the relatively large measurement error of the dietary intake measurement, they suggest moderate stability of diet over time. These findings may imply that dietary intake is changeable and suggest that disease prevention measures can be implemented in adulthood.
\end{abstract}

Age trends: Tracking: Dietary history: Longitudinal study

\begin{abstract}
Although longitudinal data on the relationship between nutrition and health status of individuals are still scarce, scientific evidence of the link between diet and a range of chronic diseases is accumulating (for example, see Block et al. 1992; Smith et al. 1995). In view of the relationship between dietary intake and chronic diseases, it is interesting to study the longitudinal development of dietary intake itself and to determine the stability of this intake. If dietary intake appears to be stable from adolescence into adulthood, measures to change dietary habits in relation to
\end{abstract}

disease prevention should be taken before the age of 12 years, as postulated by Kelder et al. (1994). If, however, dietary intake is relatively unstable, it may be changeable after the age of 12 years so that disease prevention measures would need to be taken at an older age.

Surveys of a population's food intake are carried out frequently, and age trends in individual consumption of energy and nutrients have been reported (Stephen \& Wald, 1990; Popkin et al. 1992; Norris et al. 1997; Osler et al. 1997). However, most of these studies are based on cross-sectional

\footnotetext{
Abbreviations: AGAHLS, Amsterdam Growth and Health Longitudinal Study; En \%, \% total energy intake; GEE, generalised estimating equations.

* Corresponding author: Professor H. C. G. Kemper, fax + 3120 4448181, email hcg.kemper.emgo@med.vu.nl
} 
data and are therefore not adequate to describe age trends, since the results are likely to be influenced by cohort effects. To determine whether changes over time are due to aging, repeated measurements are required of the nutrient intake for the same individuals at several points in time starting early in life.

Longitudinal research is also a prerequisite for studying the stability of energy and nutrient intakes based on individual changes. The assessment of the predictability or relative consistency of nutrient intake over time is referred to as 'tracking' (Kemper et al. 1990) and is used to describe the ability to predict future values from early measurements. The few studies that have reported tracking of nutrient intakes were carried out in young children (Stein et al. 1991; Singer et al. 1995), adolescents (Kelder et al. 1994) or in middle-aged and older adults (Jensen et al. 1984; Heaney et al. 1990; Goldbohm et al. 1995; Fernyhough et al. 1999).

The Amsterdam Growth and Health Longitudinal Study (AGAHLS) was a 20-year longitudinal study covering adolescence and adulthood. During the period 1976 to 1996-7 a group of about 200 males and females was measured eight times. Information was collected on lifestyle patterns such as daily food intake and healthrelated risk indicators such as body weight and body fat. The present study reports the dietary data of the AGAHLS. The aim of the present study was to determine whether dietary intake remains stable from adolescence into adulthood. Age trends and stability coefficients of the intakes of energy, macro- and micronutrients are presented for male and female subjects between 13 and 33 years of age.

\section{Methods \\ Study population}

The AGAHLS, described extensively elsewhere (Kemper, 1985, 1995), was a multi-disciplinary longitudinal investigation. This observational longitudinal study was carried out to assess growth, health and lifestyle from adolescence into adulthood. The subjects were recruited from a secondary school in Amsterdam. Over the period of 20 years, ninety-one females and seventy-three males were measured longitudinally from age 13 to 33 years. Dietary intake was measured eight times. In the adolescent period (13-17 years) four annual measurements were taken, starting in 1977 and ending in 1980. At the age of 21 years the fifth measurement was carried out in 1985. The sixth and seventh measurements at the ages 27 and 33 years were followed in 1991 and 1996-97. The total dropout rate was $30 \%$ over the 20 -year period. Over the first 4 years of the study selective dropout could not be shown for energy intake or dietary intake (Post, 1989). However, over the 20year period, a dropout effect was found for energy on a per $\mathrm{kg}$ body weight basis at age 13 years (W De Vente, GB Post, JWR Twisk, HCG Kemper and W van Mechelen, unpublished results). Dropouts showed a significant higher energy intake per $\mathrm{kg}$ body weight than responders (difference $15.5 \mathrm{~kJ} / \mathrm{kg}$ body weight, $95 \%$ CI $1 \cdot 15,29.9$ ).

In Table 1 the mean values and standard deviations for
Table 1. Height, body weight and the sum of four skinfolds for a Dutch cohort of men and women at the age of 33 years

(Means and standard deviations)

\begin{tabular}{lccccc}
\hline & \multicolumn{2}{c}{ Males $(n$ 73) } & & \multicolumn{2}{c}{ Females $(n$ 91) } \\
\cline { 2 - 3 } & Mean & SD & & Mean & SD \\
\hline Height $(\mathrm{m})$ & 1.83 & $(0.006)$ & & 1.70 & $(0.006)$ \\
Body weight $(\mathrm{kg})$ & 79.5 & $(8.9)$ & & 65.9 & $(9.1)$ \\
SSF* $^{*}(\mathrm{~mm})$ & 43.3 & $(16.3)$ & & 53.1 & $(20.1)$ \\
\hline
\end{tabular}

* Sum of four skinfolds.

height, body weight and sum of four skinfolds are given for the study population at the age of 33 years.

\section{Dietary assessment}

The individual dietary intake was measured by a detailed cross-check dietary history interview based on the method developed by Beal (1967) and Marr (1971) and adapted to the AGAHLS (Post, 1989). This method provided information about the usual intake of the subjects, with a reference time of 1 month. The cross-check dietary history interview consisted of two parts. First, the subject was instructed to indicate mealtimes and type of meals on an average working day (school day) and weekend day. This information provided the interviewer with an idea of the subject's pattern of eating, which facilitated the subsequent part of the interview. The second part consisted of a structured interview using a checklist (Kemper \& Van Mechelen, 1995), thoroughly checking all the consumed food and drink items during the previous month. Subjects were questioned about foods eaten during regular meals as well as between meals. These data were collected separately for working days and for weekend days. The cross-check method provides an extra check on the precision of the reporting of food items, as the interviewer can check whether the reported habits mentioned in the first part of the interview match the reported amounts in the second part of the interview. The amounts were reported in household measures. Models were used to illustrate common portion sizes (glasses, bowls, spoons, etc.) and descriptions of foods such as potatoes and fruits were used to facilitate the estimation of weights of those food items. To determine the amount of sugar in tea and coffee and the amount of butter on bread, small scales were used to weigh the amount that was chosen by the respondent.

Since it was assumed that teenagers (13-17 years) do not necessarily know all the details regarding their food consumption and the way of preparation, a questionnaire was sent to the parents during the first four measurement years (1977-1980) about details of several food items consumed by their child. Questions concerned, for example, the type of milk (skimmed or whole milk) that was consumed, the kind and quantity of meat, and the addition of butter or sauce to vegetables and potatoes. For each individual, all amounts were converted into grams for the five working days and the two weekend days.

Nutrient intake was calculated with use of the Dutch food consumption table (Stichting Nederlandse Voedingsstoffen Bestand, 1996). On the basis of the availability of 
reliable nutrient content data in this table, the following nutrients were selected: total daily energy intake (MJ; absolute and relative to body weight), protein, fat and carbohydrate ( $\mathrm{g}$ and \% total energy intake (En \%)), cholesterol (mg/MJ), Ca (mg), Fe (mg), thiamin (mg), riboflavin $(\mathrm{mg})$, pyridoxine $(\mathrm{mg})$ and ascorbic acid $(\mathrm{mg})$. Although data concerning alcohol intake are available, they were excluded from the analyses, since the variable was extremely skewed, particularly in the earlier years of the study when the majority of the youngsters did not consume any alcohol.

Since nutrient composition of all foods is necessarily identical because of the use of the Stichting Nederlandse Voedingsstoffen Bestand, (1996) nutrient-composition database, trend information derived by this method reflects changes in food choices, such as choosing low-fat milk instead of whole milk.

\section{Data analysis of trends}

The longitudinal development of the energy and nutrient intake pattern was analysed with use of a multivariate ANOVA for repeated measurements. The multivariate ANOVA tested a time effect (which can be seen as an age effect), a gender effect, as well as the interaction between time and gender. If there was a significant interaction effect $(P<0 \cdot 10)$, stratified analyses were carried out analysing the data for females and males separately. In all other analyses a critical value of $P<0.05$ was used.

\section{Tracking analysis}

Tracking of dietary factors was examined by generalised estimating equations (GEE; Twisk et al. 1996). To calculate a GEE tracking coefficient the following model was used:

$$
Y_{i t}=\beta_{0}+\beta_{1} Y_{i t 1}+\beta_{2} t+\sum_{\mathrm{J}=1}^{\mathrm{J}} \beta_{3 j} X_{i j t}+\sum_{\mathrm{K}=1}^{\mathrm{K}} \beta_{4 k} Z_{\mathrm{ik}}+\epsilon_{i t},
$$

where: $Y_{i t}$ is the observations for individual $i$ from $t_{2}$ to $t_{m}$ (where $m$ is the number of measurements); $\beta_{0}$ is the intercept; $Y_{i t 1}$ is the initial (first) observation of individual $i$ at $t_{1} ; \beta_{1}$ is the standardised regression coefficient used as the tracking coefficient; $t$ is time; $\beta_{2}$ is the regression coefficient of time; $X_{i j t}$ is the time-dependent covariate $j$ of individual $i ; \beta_{3 j}$ is the regression coefficient of timedependent covariate $j ; J$ is number of time-dependent covariates; $Z_{i k}$ is time-independent covariate $k$ of individual $i ; \beta_{4 k}$ is regression coefficient of time-independent covariate $k ; K$ is the number of time-independent covariates; and $\epsilon_{i t}$ is the measurement error of individual $i$.

In this model, the regression of the initial measurement of the independent variable $Y$ at time $t_{1} v$. the longitudinal development of $Y$ from time $t_{2}$ to $t_{m}$ was performed. The standardised regression coefficient $\beta_{1}$ can be interpreted as a tracking coefficient. Since the values of nutrient intake at each measurement were transformed into z-scores (Kleinbaum et al. 1988), the coefficient can range between -1 and 1 . However, assuming that the correlation between the repeated observations are positive, this tracking coefficient takes values between 0 (no tracking) and 1 (perfect tracking). This model also has the possibility of correcting for both time-dependent covariates (year of measurement and biological age) and time-independent covariates (gender).

The relationships between the initial value and all other values are tested simultaneously, leading to one standardised regression coefficient $(\beta)$, which can be interpreted as a longitudinal correlation coefficient or stability coefficient. In the current analysis seven data points were used (at mean ages 13, 14, 15, 16, 21, 27 and 33 years). The subjects were entered into this analysis if the initial value (at age 13 years) and the last value (at age 33 years) were present, plus two of the first four follow-up years, plus one of the two measurements in between (at age 21 or 27 years).

The major advantage of this method was that the stability coefficients were calculated using all available longitudinal data. The method also takes into account the fact that the repeated observations for each individual are not independent. In all analyses a probability level of significance of $P<0.05$ was accepted.

For the multivariate ANOVA for repeated measurements, the statistical software package SPSS (Nie et al. 1983) was used. GEE analysis was carried out with the statistical package for interactive data analysis (Gebski et al. 1992).

\section{Results}

Age and sex trends

The results of the multivariate ANOVA (Table 2) indicated that for the age period 13-33 years the absolute intake of almost all the macro- and micronutrients for both genders showed a significant time (age) effect $(P<0.001)$ with the exception of polyunsaturated fatty acids. In general, gender effects were found for nutrients calculated as absolute values, with the exception of ascorbic acid. Males generally had higher intakes than females. Gender effects disappeared when nutrients were calculated as En \%, with the exception of protein and animal protein. Furthermore, significant interaction effects between gender and time were found $(P<0.001)$ for this lifespan for the nutrients in absolute values. This finding means that females and males showed significantly different longitudinal intake patterns over time. For nutrients calculated as En \%, interaction effects were not present, with the exception of saturated fatty acids and mono- and disaccharides.

Mean total daily energy intake is given in Fig. 1 for males and females over the total 20-year study period. Daily energy intake of females was about 9.5 MJ at age 13 years. Males showed an increasing energy intake from $12.2 \mathrm{MJ}$ at age 13 years to $13.4 \mathrm{MJ}$ at age 21 years. Thereafter, it decreased to about $11.9 \mathrm{MJ}$ at age 33 years. Males showed a significantly higher energy intake than females of about $25 \%$ over the whole age-range.

When the energy intake was expressed relative to body weight, both sexes showed a decrease until the age of 27 (Fig. 2(a,b)); until that age, values for males were about 
Table 2. Results of the multivariate ANOVA of the longitudinal energy and nutrient intake pattern for a Dutch cohort of men and women between 13 and 30 years of age

\begin{tabular}{|c|c|c|c|}
\hline Nutrient & Gender effect & Time effect & Interaction effect \\
\hline Energy: kJ & 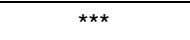 & *** & *** \\
\hline $\mathrm{kJ} / \mathrm{kg}$ weight & *** & 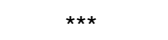 & *** \\
\hline Protein: $\mathrm{g}$ & $* \star \star$ & 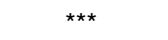 & $* * *$ \\
\hline En \% & $\star \star \star *$ & $\star \star \star *$ & NS \\
\hline Vegetable protein (En \%) & NS & $\star * \star$ & NS \\
\hline Animal protein (En \%) & $* *$ & $* * *$ & NS \\
\hline Fat: $g$ & $* \star *$ & 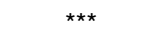 & $* \star \star$ \\
\hline En \% & NS & 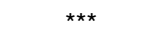 & NS \\
\hline Monounsaturated (En \%) & NS & $* * *$ & NS \\
\hline Polyunsaturated (En \%) & NS & NS & NS \\
\hline Saturated $(\mathrm{En} \%)$ & NS & 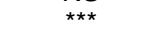 & * \\
\hline Carbohydrate: $\mathrm{g}$ & 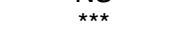 & $* \star \star$ & $\star * \star$ \\
\hline En \% & NS & 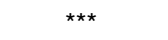 & NS \\
\hline Mono- and disaccharides (En \%) & NS & 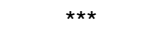 & * \\
\hline Polysaccharides (En \%) & NS & 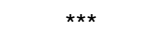 & NS \\
\hline Dietary fibre $(\mathrm{g})$ & $* \star *$ & $* \star *$ & $* \star * *$ \\
\hline Cholesterol (mg/MJ) & NS & $\star * *$ & NS \\
\hline $\mathrm{Ca}(\mathrm{mg})$ & 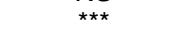 & $* * *$ & 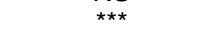 \\
\hline $\mathrm{Fe}(\mathrm{mg})$ & $\star * *$ & $* \star *$ & $\star \star \star *$ \\
\hline Thiamine (mg) & $\star \star \star *$ & $* \star \star$ & $\star \star \star *$ \\
\hline Riboflavin (mg) & 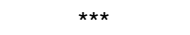 & $\star \star * *$ & $* \star *$ \\
\hline Pyridoxine (mg) & $* \star *$ & $\star * *$ & $\star \star * *$ \\
\hline Ascorbic acid (mg) & NS & $\star * \star$ & * \\
\hline
\end{tabular}

En \%, \% total energy intake.

${ }^{\star} P<0.05,{ }^{\star \star} P<0.01,{ }^{\star \star \star} P<0.001$
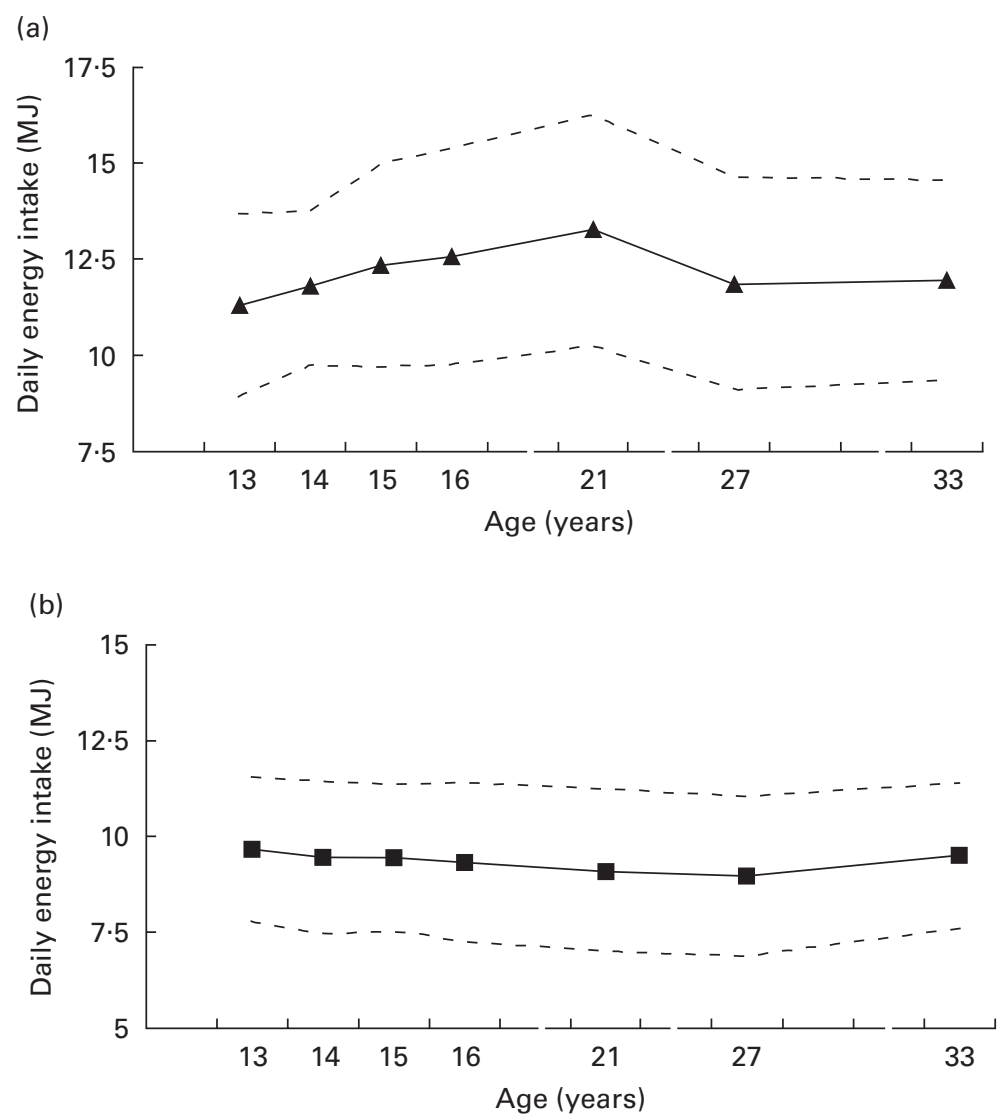

Fig. 1. The longitudinal development of the daily energy intake in seventy-three Dutch males (a) and ninety-one females (b) between the ages of 13 and 33 years. $(---),+1 \mathrm{SD}$ and $-1 \mathrm{SD}$. For details of subjects and procedures, see p. 376. 
(a)

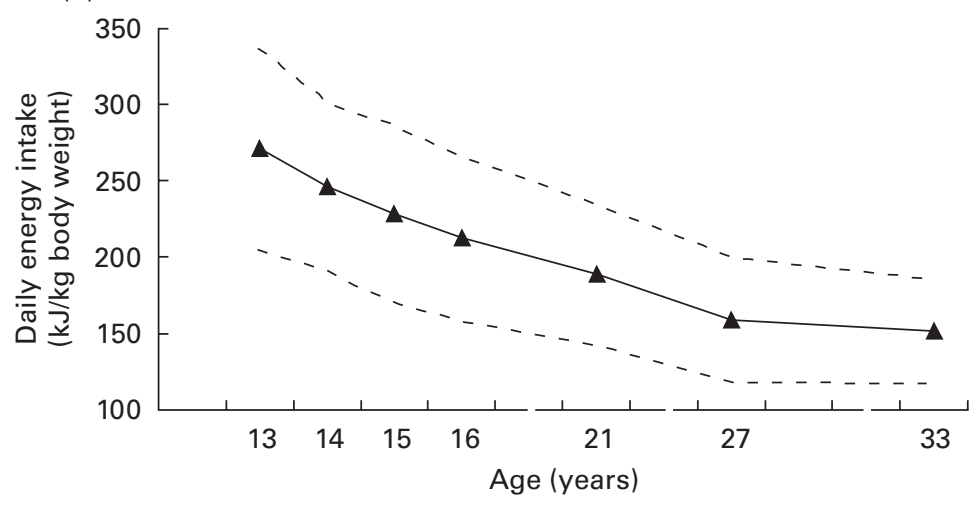

(b)

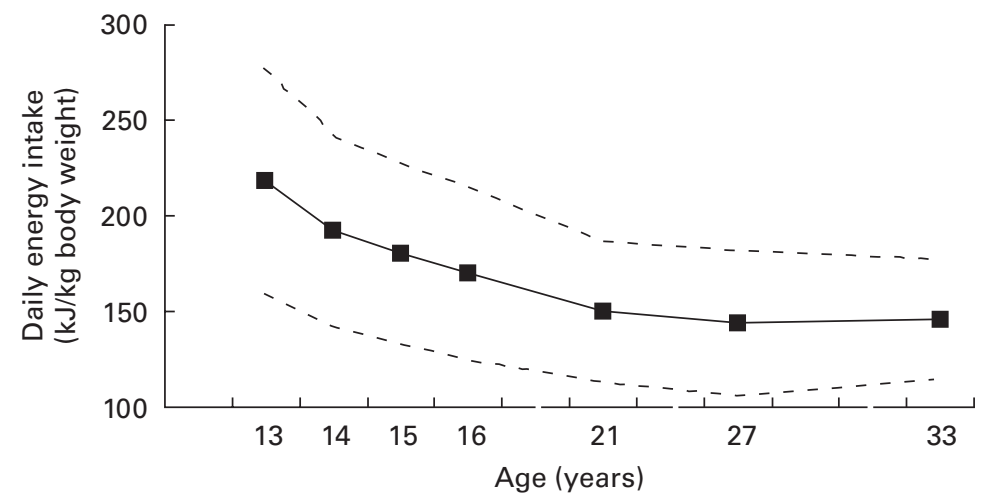

Fig. 2. The longitudinal development of the daily energy intake divided by body weight in seventy-three Dutch males (a) and ninety-one females (b) between the ages of 13 and 33 years. $(---),+1$ SD and -1 SD. For details of subjects and procedures, see p. 376 .

$25 \%$ higher than those of females. At age 33 years both sexes showed an intake of $150 \mathrm{~kJ} / \mathrm{kg}$ per d.

Daily protein intake in females did not start to increase until the age of 21 years (Fig. 3(b)) whereas males showed an $18 \%$ increase over the whole 20-year period (Fig. 3(a)). When daily protein intake was expressed as En \% for both sexes, a significant $(P<0.05)$ increase of 2 En \% was seen (in females from about 14 to 16 En \% during the 20-year period and in males from about 13 to 15 En \%).

While in absolute values the total daily fat intake in males increased from 118 to $136 \mathrm{~g}$ until age 21 years and decreased to $116 \mathrm{~g}$ at age 33 years (Fig. 4(a)), there was an important decrease in En \% from fat after adolescence from 40 to 36. Females did not show significant differences for total daily fat intake over this lifespan (Fig. 4(b)), but did show a decreasing intake in En \% from fat after age 21 years (from 39 to 37).

Total daily carbohydrate intake for females decreased until the age of 27 years and increased thereafter (Fig. 5(b)), while males increased their intake until the age of 21 years with a subsequent decrease until the age of 33 years (Fig. 5(a)). As En \% carbohydrate supplied about 47 for both sexes at age 13 years, decreasing to 45 for women and 46 for men at age 33 years.

Increasing absolute intakes over the whole longitudinal period were seen for the nutrients $\mathrm{Ca}, \mathrm{Fe}$, riboflavin, pyridoxine and ascorbic acid in males, with the increase in females starting at the age of 21 years. Decreasing intake was seen for cholesterol in females over the longitudinal period, but in males only after the age of 21 years. Ascorbic acid intake increased significantly $(P<$ 0.05 ) with age in both genders, but not with the same pattern (Fig. 6).

\section{Tracking}

Table 3 presents the results of tracking analysis between 13 and 33 years of age. For all nutrients significant $\quad(P<0.05) \quad$ stability coefficients were found, ranging between 0.28 and 0.52 . The highest tracking coefficient was found for energy intake relative to body weight $(0.52)$ with a $95 \%$ CI of $0.41,0.63$. Six of the twenty-nine nutrients showed a significant $(P<0.05)$ interaction with gender. In Table 4 (males) and Table 5 (females) the stability coefficients are shown. Males showed higher stability coefficients than females, with the highest tracking values in riboflavin and $\mathrm{Ca}$ intake (riboflavin $0.54,95 \%$ CI $0.40,0.68 ; \mathrm{Ca} 0.52,95 \%$ CI $0.36,0.68$ ). 

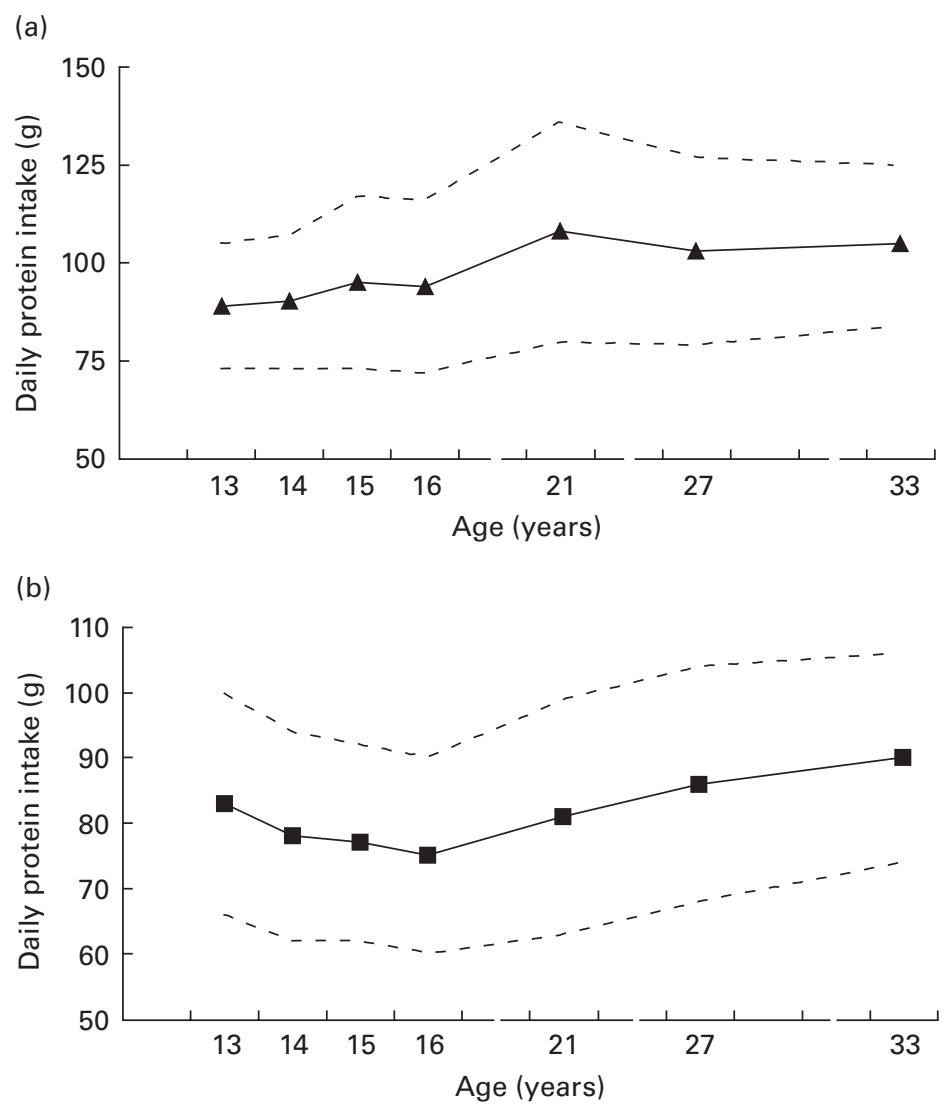

Fig. 3. The longitudinal development of the daily protein intake in seventythree Dutch males (a) and ninety-one females (b) between the ages of 13 and 33 years. $(---),+1$ SD and -1 SD. For details of subjects and procedures, see p. 376.

Table 3. Tracking coefficient (stability coefficient) and $95 \% \mathrm{Cl}$ for daily nutrient intake of a cohort of Dutch men and women, calculated with generalised estimating equationst over a period of 20 years from 1977 to 1997

\begin{tabular}{|c|c|c|}
\hline Nutrient & Stability coefficient* & $95 \% \mathrm{Cl}$ \\
\hline Energy: kJ & 0.33 & $0.22,0.43$ \\
\hline $\mathrm{kJ} /$ body weight & 0.52 & $0.41,0.63$ \\
\hline Protein: $\mathrm{g}$ & 0.36 & $0.25,0.46$ \\
\hline En \% & 0.44 & $0.34,0.54$ \\
\hline Vegetable protein: $\mathrm{g}$ & 0.30 & $0.20,0.39$ \\
\hline En \% & 0.38 & $0.27,0.50$ \\
\hline Animal protein: $\mathrm{g}$ & 0.38 & $0.26,0.51$ \\
\hline En \% & 0.41 & $0.31,0.52$ \\
\hline Fat: $g$ & 0.38 & $0.28,0.48$ \\
\hline En \% & 0.37 & $0.28,0.45$ \\
\hline Saturated fat: $\mathrm{g}$ & 0.41 & $0.32,0.50$ \\
\hline En \% & 0.36 & $0.28,0.44$ \\
\hline Monounsaturated fat: $\mathrm{g}$ & 0.37 & $0.27,0.48$ \\
\hline En \% & 0.33 & $0.25,0.42$ \\
\hline Cholesterol (g/MJ) & 0.28 & $0.18,0.38$ \\
\hline Carbohydrate: $\mathrm{g}$ & 0.31 & $0.20,0.43$ \\
\hline En \% & 0.35 & $0.25,0.44$ \\
\hline Mono/disaccharides: g & 0.34 & $0.24,0.44$ \\
\hline En \% & 0.37 & $0.27,0.48$ \\
\hline Polysaccharides: g & 0.32 & $0.20,0.55$ \\
\hline En \% & 0.34 & $0.23,0.44$ \\
\hline $\mathrm{Fe}(\mathrm{mg})$ & 0.30 & $0.20,0.40$ \\
\hline Pyridoxine (mg) & 0.31 & $0.20,0.43$ \\
\hline
\end{tabular}

En \%, \% total energy intake.

${ }^{*}$ All stability coefficients were significant $(P<0.05)$.

† For details, see p. 377.
Table 4. Tracking coefficients (stability coefficient) and $95 \% \mathrm{Cl}$ for daily nutrient intakes for Dutch males, analysed with generalised estimating equations $†$ over a period of 20 years from 1977 to 1997

\begin{tabular}{|c|c|c|}
\hline Nutrient & Stability coefficient ${ }^{*}$ & $95 \% \mathrm{Cl}$ \\
\hline Polyunsaturated fat: $\mathrm{g}$ & 0.40 & $0.20,0.60$ \\
\hline $\mathrm{Ca}(\mathrm{mg})$ & $\begin{array}{l}.00 \\
0.52\end{array}$ & $0.36,0.68$ \\
\hline Thiamin (mg) & 0.50 & $0.34,0.65$ \\
\hline Riboflavin (mg) & 0.54 & $0.40,0.68$ \\
\hline
\end{tabular}

En \%, \% total energy intake.

${ }^{*}$ All stability coefficients were significant $(P<0.05)$

† For details, see p. 377

Table 5. Tracking coefficients (stability coefficient) and $95 \% \mathrm{Cl}$ for nutrient intakes for Dutch females, analysed with generalised estimating equations $\dagger$ over a period of 20 years from 1977 to 1997

\begin{tabular}{|c|c|c|}
\hline Nutrient & Stability coefficient ${ }^{*}$ & $95 \% \mathrm{Cl}$ \\
\hline Polyunsaturated fat: $\mathrm{g}$ & $\begin{array}{l}0.14 \\
0.17\end{array}$ & $\begin{array}{l}0.05,0.23 \\
0.07,0.27\end{array}$ \\
\hline $\mathrm{Ca}(\mathrm{mg})$ & 0.34 & $0.21,0.47$ \\
\hline Thiamin (mg) & 0.31 & $0.22,0.40$ \\
\hline Riboflavin (mg) & 0.27 & $0.18,0.36$ \\
\hline
\end{tabular}

En \%, \% total energy intake.

${ }^{*}$ All stability coefficients were significant $(P<0.05)$.

† For details, see p. 377. 

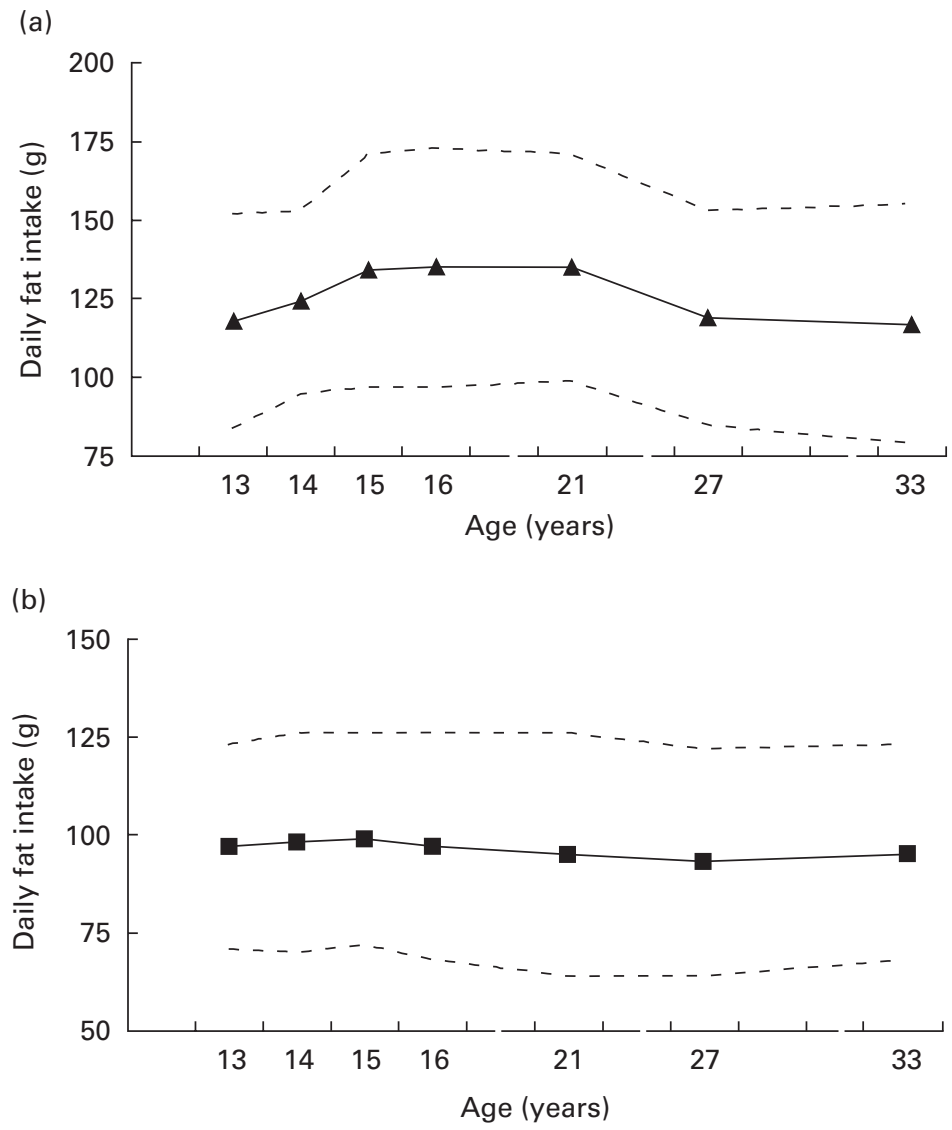

Fig. 4. The longitudinal development of the daily fat intake in seventy-three Dutch males (a) and ninety-one females (b) between the ages of 13 and 33 years. $(---),+1 \mathrm{SD}$ and $-1 \mathrm{SD}$. For details of subjects and procedures, see $\mathrm{p}$. 376.

\section{Discussion}

\section{Longitudinal trends}

The trend for daily energy intake showed a significant $(P<$ $0.001)$ increase in males until the age of 21 years and no increase in females over the 20-year time period measured in this study. When expressed relative to body weight the daily energy intake is decreased in both sexes until the age of 27 years. The age trend showed also a significant $(P<$ $0.001)$ increasing En \% from protein. The amount of animal protein, particularly, increased in females and males after the adolescent period. Nevertheless, the En \% from fat decreased to about 36 . This result was comparable with that of the Dutch population in general (Voedselconsumptiepeiling, 1998). Overall, the drop of $2-3 \%$ in En \% from fat is an encouraging indication that this study population is modifying the fat intake in their diet in line with recommendations of the Netherlands Food and Nutrition Council (1992). This finding is also reflected by the lowering trend in the daily cholesterol intake.

The carbohydrate intake also declined over the study period, to approximately $46 \mathrm{En} \%$, but this age trend is seen as undesirable. Although a favourable shift in sources of carbohydrate appeared to develop, particularly in females, a lowering of mono- and disaccharide intake (from about 127 to $120 \mathrm{~g}$ daily) was accompanied by an increasing intake of polysaccharides (from about 125 to $136 \mathrm{~g}$ daily). One factor involved in the decreasing En \% from carbohydrate and fat may be the higher contribution of alcohol to the daily energy intake over the total period (data not shown). The changes towards more healthy food habits suggest that these adults may be responding to health education messages.

A limitation of the present study is the fact that age effects cannot be separated from time-of-measurement effects, e.g. secular trends in diet. Cohort effects of the cohorts within the study were investigated during the first part of the study (Kemper, 1985) and were not found.

\section{Tracking}

The stability coefficients are in line with the outcomes of the multivariate ANOVA for repeated measurements. Although the GEE tracking coefficients of energy intake and all macro- and micronutrients were significantly different from zero, the values ranging from 0.28 to 0.45 over a period of 20 years demonstrated a stability of dietary intake that was low to moderate. This finding indicates that dietary intake during adolescence (age 13 years) seems to be a fairly weak predictor of dietary intake in the adult. In 

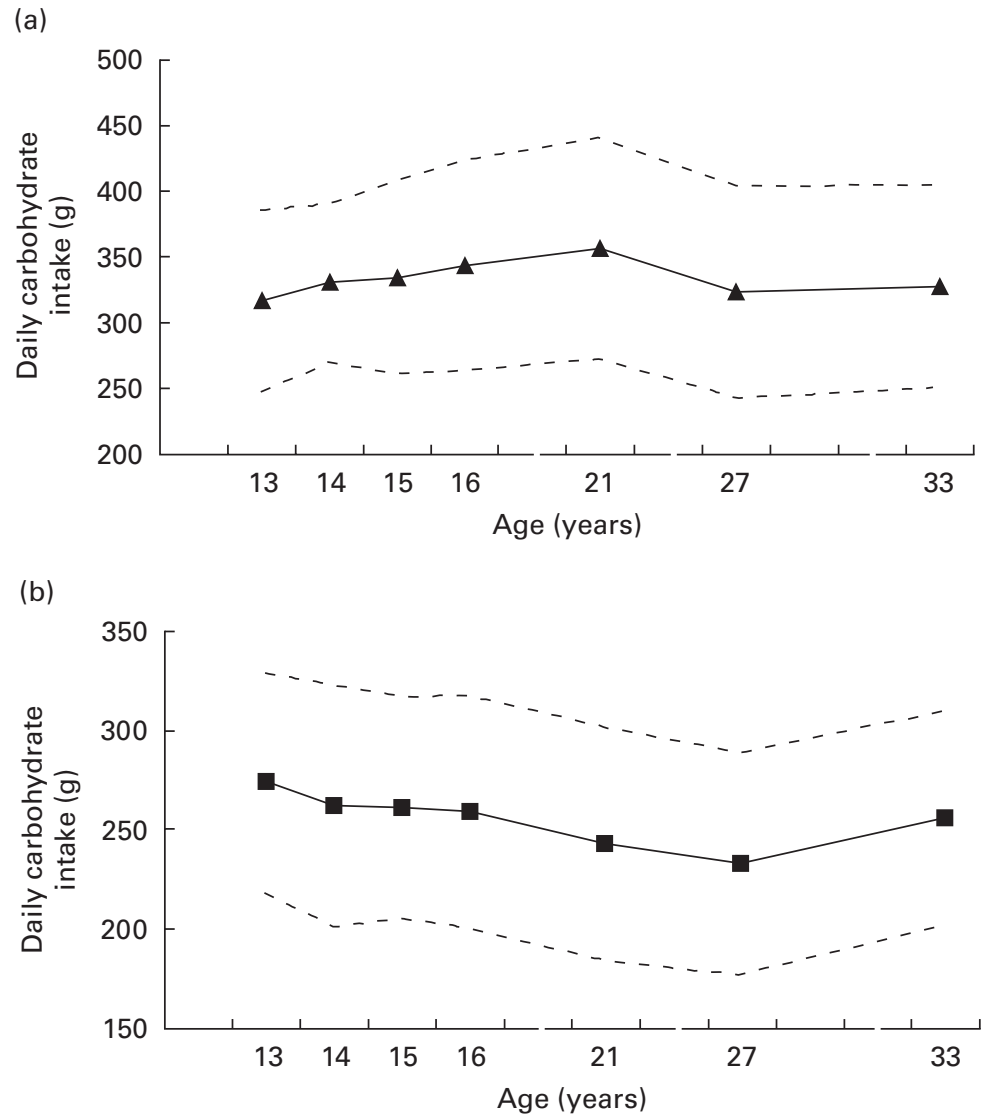

Fig. 5. The longitudinal development of the daily carbohydrate intake $(\mathrm{g})$ in seventy-three Dutch males (a) and ninety-two females (b) between the ages of 13 and 33 years. (- - ), +1 SD and -1 SD. For details of subjects and procedures, see p. 376 .

other words, when a girl or boy at the age of 13 years has a relatively low or high nutrient intake, he or she does not necessarily also have a low or high intake at the age of 33 years. These tracking coefficients are comparable with those of other lifestyle variables such as daily physical activity $(0 \cdot 34)$, but considerably lower than biological measures such as total serum cholesterol level (0.71) and sum of skinfolds (0.63; Twisk et al. 1997) over the same period. This difference may be explained by the fact that nutrient intake is a behaviour that is less determined by genetic factors than by biological variables (de Castro, $1993 a, b)$. Furthermore, it should be noted that the measurement error of lifestyle factors, such as dietary intake, is generally larger than the measurement error of biological factors such as cholesterol level. Thus, the stability coefficients in the present study are likely to be somewhat attenuated.

Comparison of tracking of nutrient intake in younger (Stein et al. 1991; Kelder et al. 1994; Singer et al. 1995) and older age-groups (Van Staveren et al. 1986; Jain et al. 1989; Goldbohm et al. 1995) gives rise to the belief that the coefficients become higher as the age of the subjects at the start of the study increased. This finding suggests that nutrient intakes tend to stabilise with increasing age. Although Kelder et al. (1994) have demonstrated relatively good tracking of dietary intake during the 6 years of adolescence, the current study postulates that dietary intake does not stabilise in this period, as shown by the relatively moderate predictability of dietary intake during adulthood by the dietary intake during adolescence. Since in other longitudinal studies GEE tracking coefficients had not been calculated over a similarly long period, it was not possible to compare the outcomes.

\section{Dietary intake measurement and calculation}

Although the study design and diet-assessment methodologies were identical for all the measurement years, and the validity and reproducibility of the cross-check dietary history used in the present study have been demonstrated (Post, 1989), several limitations of the nutritional data can be noted. Principally, all dietary interviews over the years were conducted by the same dietitian, but for the last measurement (1996-7) two other interviewers were involved. In order to minimise the risk of systematic differences between the interviewers, they were thoroughly trained and attuned to the same procedure.

Another limitation of the current study is the use of one nutrient database (Stichting Nederlandse Voedingsstoffen Bestand, 1996) for the calculation of nutrient intake data measured between 1977 and 1997. The nutrient database for the years 1976-80 gave different compositions from 
(a)

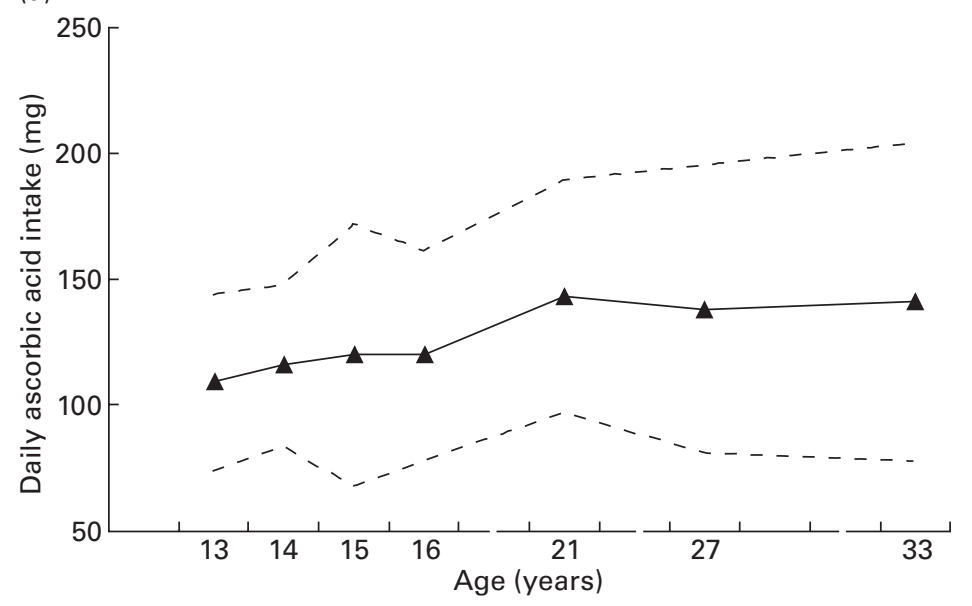

(b)

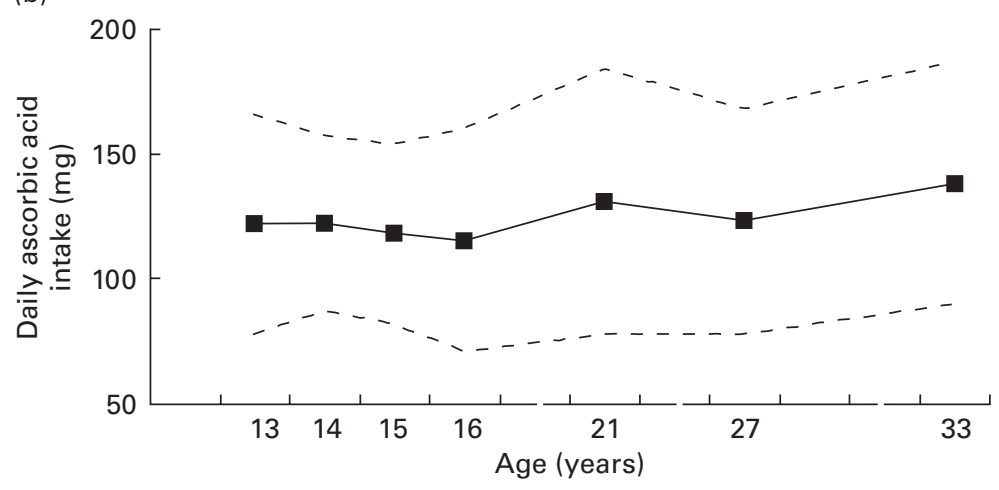

Fig. 6. The longitudinal development of the daily ascorbic acid intake (mg) in seventy-three Dutch males (a) and ninety-two females between the ages of 13 and 33 years. $(---),+1$ SD and -1 SD. For details of subjects and procedures, see p. 376.

that used in 1996-7. During these 20 years not only has a more precise method of analysing food items been developed, but also the composition of ingredients has changed; for example, there has been a reduction in the fat content of meat products and milk, resulting in a difference in the nutrients offered. We have chosen to use only the database of 1996-7, making the assumption that the nutrient content was more or less identical. It is likely that the use of different systems would introduce additional errors in the estimation of nutrient intake. A shift towards less-frequent consumption of important fat sources or new foods with less fat not included in the interview will affect the magnitude, but not the direction, of the observed trend. Norris et al. (1997) described US trends in nutrient intake between 1987 and 1992, analysed using identical food composition databases of 1992 or food composition tables of the particular year of measurement. When analysed with the identical 1992 database, a further decrease in fat intake was shown.

A third limitation, common to all self-report methods, is response bias. Repeated testing can have an effect by under-reporting, as has been shown in our study during adolescence (Post, 1989) and in other studies (Black et al. 1991; Goldberg et al. 1991). Furthermore, participants may answer in a socially desirable way; for example, reporting fewer 'fatty foods' because health messages had emphasised the desirability of lowering fat content in the diet. During a period of 20 years various health messages could have influenced the reported dietary intake. It is often suggested in the literature that women are more prone to socially desirable answers than men (Westerterp et al. 1992). It is difficult to determine the extent to which the subjects in our study were affected. If it is true that underreporting was more present in females than in males from the start of the AGAHLS, or whether they started doing this during the research period, part of the gender effects or gender $\times$ time interaction effects could be explained by this under-reporting. With regard to stability coefficients, substantial under-reporting by part of the research population, resulting in substantially lower dietary intake for the subpopulation that under-reported in comparison with that of the subpopulation that did not under-report, most probably results in inflation of these coefficients. In this manner, the cross-sectional differences are relatively large in comparison with the individual changes over time. However, if females (or another subpopulation) started to under-report their dietary intake during the study, the stability coefficients are most likely to be deflated. In this 
way changes are artificial, since they are caused by a response shift and do not reflect actual changes in dietary intake.

\section{Conclusions}

From the results of the present study it can be concluded that over a period of 20 years the dietary intake of a group of Dutch males and females changed considerably over time. Although the stability coefficients may be somewhat attenuated due to measurement error, stability of the individual nutrient intake over 20 years can be considered as moderate, and does not allow a good prediction to be made from the teenage period to the adult period. These outcomes suggest that dietary intake has not stabilised during adolescence, and may suggest that dietary intake, in principle, can be quite changeable. However, to date, the health promotion strategies designed to change dietary intake do not seem to have been sufficiently effective.

\section{References}

Beal VA (1967) The nutritional history in longitudinal research. Journal of the American Dietetic Association 51, 426-432.

Black AE, Goldberg GR, Jebb SA, Livingtone MB, Cole TJ \& Prentice AM (1991) Critical evaluation of energy intake data using fundamental principles of energy physiology: 2. Evaluating the results of published surveys. European Journal of Clinical Nutrition 45, 583-599.

Block G, Patterson B \& Subar A (1992) Fruit, vegetables, and cancer prevention: a review of the epidemiological evidence. Nutrition and Cancer 18, 1-29.

de Castro JM (1993a) Genetic influences on daily intake and meal patterns of humans. Physiology and Behavior 53, 777-782.

de Castro JM (1993b) Independence of genetic influences on body size, daily intake, and meal patterns of humans. Physiology and Behavior 54, 633-639.

Fernyhough LK, Horwath CC, Campbell AJ, Robertson MC \& Busby WJ (1999) Changes in dietary intake during a 6-year follow-up of an older population. European Journal of Clinical Nutrition 53, 216-225.

Gebski V, Leung O, McNeil D \& Lunn D (1992) SPIDA User Manual, version 6. Eastwood, NSW Australia: University of Macquaire.

Goldberg GR, Black AE, Jebb SA, Cole TJ, Murgatroyd PR, Coward WA \& Prentice AM (1991) Critical evaluation of energy intake data using fundamental principles of energy physiology: 1. Derivation of cut-off limits to identify underrecording. European Journal of Clinical Nutrition 45, 569-581.

Goldbohm RA, van't Veer P, van den Brandt PA, van't Hof MA, Brants HAM, Sturmans F \& Hermus RJJ (1995) Reproducibility of a food frequency questionnaire and stability of dietary habits determined from five annually repeated measurements. European Journal of Clinical Nutrition 49, 420-429.

Heaney RP, Davies KM, Recker RR \& Packard PT (1990) Longterm consistency of nutrient intakes in human. Journal of Nutrition 120, 869-875.

Jain M, Howe GR, Harrison L \& Miller AB (1989) A study of repeatability of dietary data over a seven-year period. American Journal of Epidemiology 129, 422-429.

Jensen OM, Wahrendorf J, Rosenqvist A \& Geser A (1984) The reliability of questionnaire-derived historical dietary information and temporal stability of food habits in individuals. American Journal of Epidemiology 120, 281-290.
Kelder SH, Perry CL, Klepp K \& Lytle LL (1994) Longitudinal tracking of adolescent smoking, physical activity, and food choice behaviors. American Journal of Public Health 84, 11211126.

Kemper HCG (1985) Growth, Health and Fitness of Teenagers: Longitudinal Research in International Perspective. Medicine and Sport Science Series no. 20 Basel and New York: Karger.

Kemper HCG (1995) The Amsterdam Growth Study: A Longitudinal Analysis of Health, Fitness and Lifestyle. HKP Sport Science Monograph Series no. 6 Champaign, IL: Human Kinetics.

Kemper HCG, Snel J, Verschuur R \& Storm-van Essen L (1990) Tracking of health and risk indicators of cardiovascular diseases from teenager to adult: Amsterdam Growth and Health Study. Preventive Medicine 19, 642-655.

Kemper HCG \& Van Mechelen W (1995) Methods and measurements used in the longitudinal study. In The Amsterdam Growth Study: A longitudinal analysis of health, fitness and lifestyle. HKP Sport Science Monograph Series no. 6, pp. 39 [HCG Kemper, editor]. Champaign, IL: Human Kinetics.

Kleinbaum DG, Kupper LL \& Muller KE (1988) Applied Regression Analysis and Other Multivariate Methods. Boston, MA: PWS-KENT Publishing Co..

Marr JW (1971) Individual dietary surveys: purpose and methods. World Review of Nutrition and Dietetics 13, 105-164.

Netherlands Food and Nutrition Council (1992) Nederlandse Voedingsnormen 1989 (Dutch Food Norms 1989). 2nd ed. The Hague, The Netherlands: Voorlichtingsbureau voor de Voeding.

Nie NH, Hull CH, Jenkins JG, Steinbrenner K \& Bent DH (1983) SPSS: Statistical Packages for the Social Sciences. New York: McGraw-Hill.

Norris J, Harnack L, Carmichael S, Pouane T, Wakimoto P \& Block G (1997) US trends in nutrient intake: the 1987 and 1992 national health interview surveys. American Journal of Public Health 87, 740-746.

Osler M, Heitmann BL \& Schroll M (1997) Ten year trends in the dietary habits of Danish men and women - cohort and crosssectional data. European Journal of Clinical Nutrition 51, 535541.

Popkin BM, Haines PS \& Patterson RE (1992) Dietary changes in older Americans, 1977-1987. American Journal of Clinical Nutrition 55, 823-830.

Post GB (1989) Nutrition in adolescence: a longitudinal study in dietary pattern from teenager to adult. PHD Thesis, Agricultural University Wageningen, The Netherlands.

Singer MR, Moore LL, Garrahie EJ \& Ellison RC (1995) The tracking of nutrient intake in young children: The Framingham Children's study. American Journal of Public Health 85, 1673 1677.

Smith SA, Campbell DR, Elmer PJ, Martini MC, Slavin JL \& Potter JD (1995) The University of Minnesota cancer prevention research unit vegetable and fruit classification scheme (United States). Cancer Causes and Control 6, 292-302.

Stein AD, Shea S, Basch CE, Contento IR \& Zybert P (1991) Variability and tracking of nutrient intakes of pre-school children based on multiple administrations of the 24-hour dietary recall. American Journal of Epidemiology 134, 1427-1437.

Stephan A \& Wald N (1990) Trends in individual consumption of dietary fat in the United States, 1920-1984. American Journal of Clinical Nutrition 52, 457-469.

Stichting Nederlandse Voedingsstoffen bestand (1996) Nevo Tabel 1996 (Dutch Food Composition Table 1996). Den Haag, The Netherlands: Voorlichtingsbureau voor de Voeding.

Twisk JWR, Kemper HCG, Mellenbergh GJ, van Mechelen W \& Post GB (1996) Relation between the longitudinal development of lipoprotein levels and lifestyle parameters during adoles- 
cence and young adulthood. Annals of Epidemiology 6, 246256.

Twisk JWR, Kemper HCG, van Mechelen W \& Post GB (1997) Tracking of risk factors for coronary heart disease over a 14year period: A comparison between lifestyle and biological risk factors with data from the Amsterdam Growth and Health Study. American Journal of Epidemiology 145, 888-898.

Van Staveren WA, West CE, Hoffmans MDA, Bos P, Kardinaal AF, van Poppel GA, Schipper HJ, Hautvast JG \& Hayes RB (1986) Comparison of contemporaneous and retrospective estimates of food consumption made by a dietary history method. American Journal of Epidemiology 123, 884-893.

Voedselconsumptiepeiling (1998) Zo eet Nederland 1996 (That's How the Dutch Eat 1996). Den Haag, The Netherlands: Voedingscentrum.

Westerterp KR, verboeket-Van de Venne WPHG, Meijer GAL \& Ten Hoor F (1992) Self-reported intake as a measure for energy intake, a validation against doubly labelled water. In Obesity in Europe 91, pp. 17-22 [G Ailhaud, B Guy-Graud, M Lafontau and D Ricquier, editors]. London: John Libbey. 